Western University

Scholarship@Western

Biology Publications

Biology Department

$1-1-2017$

\title{
Does cold activate the Drosophila melanogaster immune system?
}

Golnaz Salehipour-Shirazi

Laura V Ferguson

Brent J Sinclair

Follow this and additional works at: https://ir.lib.uwo.ca/biologypub

Part of the Biology Commons

Citation of this paper:

Salehipour-Shirazi, Golnaz; Ferguson, Laura V; and Sinclair, Brent J, "Does cold activate the Drosophila melanogaster immune system?" (2017). Biology Publications. 84.

https://ir.lib.uwo.ca/biologypub/84 
1 Does cold activate the Drosophila melanogaster immune system?

2 Golnaz Salehipour-shirazi*, Laura V. Ferguson*, Brent J. Sinclair ${ }^{\dagger}$

3 Department of Biology, The University of Western Ontario, London, ON, Canada N6A 5B7

4

$5 \quad *$ Contributed equally

6

7 †Author for correspondence: $\underline{\text { bsincla7@uwo.ca }}$

8 Department of Biology, University of Western Ontario, London, ON, Canada N6A 5B7. Phone:

9 1-519-661-2111x83138. Fax 1-519-661-3935

10 


\section{Abstract}

Cold exposure appears to activate aspects of the insect immune system; however, the 13 functional significance of the relationship between cold and immunity is unclear. Insect success

14 at low temperatures is shaped in part by interactions with biotic stressors, such as pathogens, thus

15 it is important to understand how and why immunity might be activated by cold. Here we

16 explore which components of the immune system are activated, and whether those components

17 differ among different kinds of cold exposure. We exposed Drosophila melanogaster to both 18 acute $\left(2 \mathrm{~h},-2^{\circ} \mathrm{C}\right)$ and sustained $\left(10 \mathrm{~h},-0.5^{\circ} \mathrm{C}\right)$ cold, and measured potential (antimicrobial peptide

19 expression, phenoloxidase activity, haemocyte counts) and realised (survival of fungal infection,

20 wound-induced melanisation, bacterial clearance) immunity following recovery. Acute cold

21 increased circulating haemocyte concentration and the expression of Turandot-A and diptericin,

22 but elicited a short-term decrease in the clearance of gram-positive bacteria. Sustained cold

23 increased the expression of Turandot- $A$, with no effect on other measures of potential or realised

24 immunity. We show that measures of potential immunity were up-regulated by cold, whereas

25 realised immunity was either unaffected or down-regulated. Thus, we hypothesize that cold-

26 activation of potential immunity in Drosophila may be a compensatory mechanism to maintain

27 stable immune function during or after low temperature exposure.

29 Key Words: thermal biology, immune system, trade-off, cross-talk, damage 


9

\section{Introduction}

Understanding how the physiological responses by animals to multiple biotic and abiotic stressors are linked through cross-talk or cross-tolerance is key to understanding the multidimensional impacts of a changing climate (Kaunisto et al., 2016; Sinclair et al., 2013). For example, insects appear to increase immune activity after cold exposure (Marshall and Sinclair, 2011; Zhang et al., 2011), which could modify host-pathogen relationships with changing winters (Williams et al., 2015). However, it is unclear whether these putatively-linked responses to distinct stressors are non-adaptive by-products of a generalised stress response, or the result of a functional coadaptation reflecting a link between pathogens and cold (Sinclair et al., 2013).

There are several, non-mutually exclusive hypotheses to explain why cold exposure might increase immune activity in insects. Cold exposure may non-adaptively activate immunity through activation of pathways shared with the stress response (Sinclair et al., 2013); however, recovery from cold exposure is already energetically costly (MacMillan et al., 2012), and it should be selectively disadvantageous to increase the cost associated with cold exposure by unnecessarily increasing resistance to pathogens. Instead, cold-induced immune activity may be an adaptive response to immune stress associated with cold (Sinclair et al., 2013). Among adaptive responses, immune processes could be required for repair of damage from cold exposure, or the presence of cold-active pathogens may have selected for increased immune activity following exposure to low temperatures (Sinclair et al., 2013).

0

To begin to understand the functional significance of cold-induced immunity, we can explore the effects of cold exposure on multiple components of the immune system. Measures of 
53 potential immunity (sensu Fedorka et al., 2007), such as gene expression, provide insight into

54 affected pathways (e.g. Toll vs. IMD), and the potential for shared responses between the

55 immune system and the stress response. Measures of realised immunity (sensu Fedorka et al.,

56 2007) provide insight into whether or not the ability to fight or survive pathogen infection is

57 affected by cold exposure, and thus whether immune activation may be a response to pathogen

58 threat at low temperatures.

The physiological responses to cold differ among insects and kinds of cold exposure

61 (Zachariassen, 1985). Specifically, brief exposure to intense cold (e.g. $2 \mathrm{~h}$ at $-5{ }^{\circ} \mathrm{C}$ in $D$.

62 melanogaster) is thought to cause cold shock injury, such as membrane phase transition (Drobnis

63 et al., 1993) or initiation of apoptosis (Yi et al., 2007), while longer cold exposures appear to

64 cause stress by disrupting ion and water balance (MacMillan et al., 2012). We can use these

65 differences in the physiological response to different types of cold exposure to further explore

66 the function of cold-induced up-regulation of immunity. For example, in Drosophila

67 melanogaster, short, prolonged, and repeated cold exposures elicit unique transcriptomic profiles

68 including of the expression of genes associated with immunity (Zhang et al., 2011), which

69 suggests that the relationship between cold and immunity depends on the physiological response

70 to a particular type of cold exposure. Therefore, if a suite of immune responses is specific to a

71 particular type of cold exposure, we can begin to infer how this activity is linked to the

72 physiological response to cold, and thus why immune activity might be activated.

73

To begin to understand why the immune system is linked to cold exposure, and what the

75 consequences of this relationship may be, we quantified multiple components of both potential 
76 and realised immunity (Fedorka et al., 2007) in Drosophila melanogaster following two cold

77 exposures that differed in both duration and temperature, and which are likely to provoke

78 different physiological responses to cold, and which have previously been shown to elicit

79 upregulation of immune-related genes (Zhang et al., 2011): acute $\left(2 \mathrm{~h}\right.$ at $\left.-2^{\circ} \mathrm{C}\right)$ and sustained

$80\left(10 \mathrm{~h}\right.$ at $\left.-0.5^{\circ} \mathrm{C}\right)$. Overall, we aim to use cold-activation of insect immunity as a system in which

81 to tease apart the links between responses to abiotic and biotic stressors, and highlight the

82 importance of considering the physiological connections between different stressors in insects.

\section{2. Materials and methods}

$85 \quad 2.1$ Rearing and cold exposures

86 An outbred mass-reared population of wild-type Drosophila melanogaster collected in London

87 and Niagara-on-the-Lake, ON, Canada, in 2008 (described by (Marshall and Sinclair, 2010) was

88 reared on a banana-cornmeal-agar medium at $21.5^{\circ} \mathrm{C}, 60 \% \mathrm{RH}$, under 14L:10D. Before

89 beginning the experiment, we reared flies for several generations on a medium containing

90 tetracycline and methylparaben (to eliminate Wolbachia sp., confirmed with PCR) (Carrington et

91 al., 2010); flies used in experiments were then reared for at least four generations on banana-

92 cornmeal-agar medium without antibiotics or antifungals. We collected newly-eclosed virgin

93 females under $\mathrm{CO}_{2}$, and allowed them to recover for seven days to minimise the physiological

94 effects of anaesthesia (Nilson et al., 2006). Flies were exposed to cold in groups of 10 in food

95 vials (3-15 vials per experiment/exposure/treatment) in aluminium blocks cooled from

96 refrigerated circulators (c.f. Nyamukondiwa et al., 2011); flies were in darkness during the cold

97 exposure, thus cold exposures were performed during the hours in which flies would usually

98 experience darkness. We exposed groups of flies to acute $\left(-2^{\circ} \mathrm{C}, 2 \mathrm{~h}\right)$ or sustained $\left(-0.5^{\circ} \mathrm{C}, 10 \mathrm{~h}\right)$ 
99 cold in vials with food to maintain high humidity. Controls were handled identically to their

100 corresponding cold-exposed group, but maintained at $21.5^{\circ} \mathrm{C}$. After cold exposure, we returned

101 flies to rearing conditions for 2-6h [depending on the immune response to be measured, and

102 based on previous (Zhang et al., 2011) or preliminary experiments], during which time all flies

103 recover, and then measured immune activity.

104

1052.2 Potential immunity

106 To determine the effect of cold exposure on potential immunity, we measured circulating

107 haemocyte concentration (CHC) and phenoloxidase activity (PO) in haemolymph samples, and

108 mRNA abundance of immune-related genes (IMD pathway: attacin, cecropin, diptericin; Toll

109 pathway: drosocin, drosomycin; IMD and Toll: defensin and metchnikowin; Jak-STAT pathway:

110 Turandot-A and virus-induced RNA 1). Statistical analyses were performed in SPSS. We used t-

111 tests (CHC and mRNA abundance) or ANOVA (PO activity) to compare differences in potential

112 immunity among treatments.

\section{2.2.1 Circulating haemocyte counts}

115 To estimate $\mathrm{CHC}$, we collected haemolymph $(\mathrm{n}=10$ per treatment) following MacMillan and 116 Hughson (2014), diluted haemolymph in anticoagulant buffer [0.55\% W/V cresyl violet, $0.5 \%$

117 ethylene-diamine-tetraacetic acid in phosphate buffered saline (PBS)] and counted haemocytes in 118 a Neubauer improved haemocytometer at $400 \times$ magnification. 
121 We collected haemolymph following MacMillan and Hughson (2014) and pooled haemolymph

122 from 8-10 flies under oil, for a final volume of $0.1 \mu \mathrm{L}(\mathrm{n}=3-5$ pooled samples per treatment).

123 We diluted the haemolymph in $10 \mu \mathrm{L}$ of PBS, snap-froze the samples in liquid nitrogen, and

124 stored them at $-80^{\circ} \mathrm{C}$ until use. We measured PO activity spectrophotometrically using L-

125 dihydroxyphenylalanine (L-DOPA; $4 \mathrm{mg} / \mathrm{mL})$ as the substrate. We expressed phenoloxidase

126 activity as change in absorbance at $492 \mathrm{~nm} / \mathrm{min} / \mu \mathrm{L}$, obtained during the linear portion of the

127 reaction (Wilson et al., 2001).

128

129

\subsubsection{Measurement of relative $m R N A$ abundance with $q P C R$}

130

131

132

133

134

135

136

137

138

139

140

141

142

143

To investigate the expression of genes associated with Toll, IMD, and JAK/STAT pathways, we quantified the expression of genes related to products or intermediate components of pathways by quantitative real-time polymerase chain reaction (RT-qPCR) (Bing et al., 2012). For each cold exposure treatment, we snap-froze flies in liquid nitrogen $6 \mathrm{~h}$ following cold exposure (Zhang et al., 2011) and extracted and pooled RNA from 30 frozen flies per sample $(n=5$ pooled samples per treatment) using Trizol Reagent. We dissolved the extracted RNA pellet in $60 \mu \mathrm{l}$ RNasefree water and determined the total RNA concentration and purity ratio at 260 and $280 \mathrm{~nm}$ absorbance using a NanoDrop 2000 spectrophotometer and associated software. Only samples with a $260 / 280$ ratio of 1.98 or more were used. To remove DNA contaminants, we treated the RNA samples with DNase. We mixed one microgram RNA from each sample with $1 \mu$ of DNase I Amp Grade and $1 \mu 1$ of 10X DNase I Reaction Buffer. After incubation at room temperature for $15 \mathrm{~min}$, we added $1 \mu \mathrm{l}$ of $25 \mathrm{mM}$ EDTA incubated the samples at $65^{\circ} \mathrm{C}$ for 5 min to inactivate the DNase. We cooled the samples on ice before using them for cDNA synthesis. To synthesize cDNA, we added $2 \mu$ l of oligodT, $4 \mu \mathrm{l}$ qScript Flex Reaction Mix (5×) 
144 and $1 \mu \mathrm{l}$ qScript Reverse Transcriptase to $1 \mu \mathrm{g}$ RNA of each sample. We then treated the samples 145 at $42{ }^{\circ} \mathrm{C}$ for $75 \mathrm{~min}$ and $85^{\circ} \mathrm{C}$ for $5 \mathrm{~min}$. To amplify the cDNA, we used SYBR Green Master 146 Mix. To normalize the data obtained from the target genes, we used $R p l-32$ as a reference gene 147 (Zaidman et al., 2011). To determine the efficiency of primers at different cDNA concentrations, 148 we created standard curves of target genes and the reference gene using seven different 149 concentrations of mixed cDNA samples (0, 4, 16, 64, 256, 1024 and 4096-fold dilution). We 150 calculated threshold cycle $(\mathrm{Ct})$ values using CFX Manager Software ver. 2.1 (Bio-Rad) and we 151 calculated and normalised the expression ratio of target genes relative to controls. We 152 standardised all values to Rpl-32 as a housekeeping gene, and to controls using $\Delta \Delta \mathrm{Ct}$ (Pfaffl, 153 2001).

$155 \quad 2.3$ Realised immunity

156 To examine the effect of cold exposure on realised immunity, we measured survival after topical 157 application of the fungus Metarhizium anisopliae (Le Bourg et al., 2009), wound-induced 158 melanisation, and the ability to clear gram-positive (Bacillus subtilis) and gram-negative 159 (Escherichia coli) bacteria from the haemolymph (McKean and Nunney, 2001). Flies were 160 briefly anaesthetized with $\mathrm{CO}_{2}$ prior to all measures. Statistical analyses were performed in $\mathrm{R}(\mathrm{R}$ 161 Development Core Team, 2010). We used a linear mixed-effects model (fungal infections; "vial" 162 as a covariate), a general linear model (wounding response) and a three-way ANOVA (bacterial 163 clearance) to compare differences in realised immunity among treatments. 
165 Immediately after cold exposure, we pierced flies on the dorsal surface using a sterilized No. 000

166 insect pin (Figure S1). We photographed the pierced area of ten flies from each treatment group

167 at 6,12 , and $24 \mathrm{~h}$ post-cold-exposure. We then quantified melanisation by measuring the mean

168 gray value of the pierced area using Image $\mathrm{J}$ software. To compare piercing-induced

169 melanisation between cold-treated and control flies, we recorded the gray value of the pierced

170 area of treated and control flies at specific time points $(0,6$, and $12 \mathrm{~h}$ and after cold exposure).

171 Darker colors with lower gray values indicated more piercing-induced melanisation.

172

\section{$173 \quad$ 2.3.2 Fungal infection}

174 We obtained the broadly entomopathogenic fungus Metarhizium anisopliae (strain 2575, USDA,

175 Ithaca, NY, USA) from Dr. Michael Bidochka (Brock University, St. Catharine's, ON, Canada).

176 Metarhizium anisopliae is commonly isolated from temperate soils and the overwintering

177 habitats of insects (Bidochka et al., 1998), and we performed preliminary experiments to ensure

178 that the fungus was lethal to flies at their rearing temperature of $21.5^{\circ} \mathrm{C}$. Following $6 \mathrm{~h}$ of

179 recovery from cold exposure, we used the method of Le Bourg et al. (2009) for infecting flies by

180 shaking them on an agar plate (30 s) with sporulating fungus. Non-infected controls of each

181 group were shaken on a sterile plate. We returned groups of flies to vials $(\mathrm{n}=8-10$ per vial; 5-7

182 vials per treatment) at $21.5^{\circ} \mathrm{C}$ and monitored survival every $24 \mathrm{~h}$ for $16 \mathrm{~d}$.

$184 \quad$ 2.3.3 Bacterial clearance

185 To compare the ability of control and cold-exposed flies to clear bacteria from the haemolymph, 186 we injected flies ( $\mathrm{n}=4-9$ per infection, per treatment) with streptomycin-resistant gram-positive 187 (B. subtilis) and streptomycin-resistant gram-negative (E. coli) bacteria suspended in PBS, 
188 following (McKean and Nunney, 2001), with some modifications. We selected flies haphazardly

189 from each treatment group and injected $105 \mathrm{~nL}\left(\sim 1 \times 10^{4} \mathrm{CFU}\right)$ into the thorax through a glass

190 capillary needle attached to a hydraulic manual microinjector (Sutter Instrument, Novato, CA,

191 USA) $2 \mathrm{~h}$ or $6 \mathrm{~h}$ post-cold-exposure. We homogenized whole flies in $90 \mu \mathrm{L}$ PBS 30s post-

192 injection (to confirm the concentration of injection), or after $5 \mathrm{~h}$ or $12 \mathrm{~h}$ recovery at $21.5^{\circ} \mathrm{C}$. We

193 diluted and plated $10 \mu \mathrm{L}$ of each homogenate in four replicated spots on Luria broth agar

194 containing streptomycin $(25 \mu \mathrm{g} / \mathrm{mL})$, incubated the plates $\left(37^{\circ} \mathrm{C}, 24 \mathrm{~h}\right)$ and counted the number of

195 colony-forming units.

197 3. Results

$198 \quad 3.1$ Potential immunity

199 Acute, but not sustained, cold, significantly increased CHC compared to controls (Fig. 1; Table

200 1). We did not detect any difference in PO activity among treatments $\left(F_{2,9}=1.09, p=0.38\right)$.

201 Expression of diptericin increased following acute cold, and expression of Turandot-A increased

202 relative to controls following both acute and sustained exposures (Fig. 3; Table 1). Expression of

203 metchnikowin was higher after acute than sustained cold exposure (Fig 3C; Table 1). No other

204 changes in gene expression were observed (Table S2).

205

$206 \quad 3.2$ Realised immunity

207 Neither acute nor sustained cold changed the susceptibility of flies to fungal infection (Fig. 4;

208 Table 1). Only one uninfected control died over the course of the experiment in both the acute

209 and control treatments, and no mortality occurred in uninfected flies from the sustained cold

210 treatment; we did not detect any significant difference in survival among uninfected controls 
211 (sustained vs control: $\mathrm{t}_{9}=0.92, \mathrm{p}=0.38$; acute vs control: $\mathrm{t}_{9}=0.11, \mathrm{p}=0.91$ ). Wound-induced

212 cuticle darkening was unchanged by either treatment (Fig. 5; Table 1). Clearance of gram-

213 positive bacteria decreased in flies exposed to acute cold when measured within $2 \mathrm{~h}$ of cold

214 exposure (Fig 6; Table 1), but bacterial-clearance ability recovered rapidly: following 6h of

215 recovery from cold, treatment did not affect clearance (Fig. 6; Table 1).

216

\section{4. Discussion}

We explored the effects of acute and sustained cold exposure on immune activity in

Drosophila melanogaster. Acute cold exposure increased potential immunity (more circulating haemocytes and increased expression of diptericin and TurandotA), but decreased one measure of realised immunity (gram-positive bacterial clearance immediately after cold exposure). Sustained cold exposure also increased Turandot- $A$ expression but did not affect realised 223 immunity.

All cold-exposed flies were in chill coma (MacMillan et al., 2015), and these cold exposures have measurable non-lethal fitness impacts (Marshall and Sinclair, 2010), as well as

227 transcriptomic profiles that suggest that they are both stressful exposures (Zhang et al., 2011). However, because sustained cold exposure did not elicit an increase in immune activity, whereas 229 acute cold exposure increased potential immunity, it seems unlikely that cold-induced immune 230 activity is a by-product of a general stress response. Instead, we suggest that acute cold led to 231 increased cold shock injury [e.g. tissue damage associated with apoptosis (Yi et al., 2007) or 232 membrane phase transitions (Lee et al., 2006)] relative to the sustained exposure, which signaled 233 for an increase in potential immunity via direct signals from apoptotic or necrotic cells 
234 (Maltzinger, 1998). For example, repeated cold exposure both increases tissue damage as well

235 as resistance to fungal infection in Pyrrharctia isabella, (Marshall and Sinclair, 2011),

236 suggesting that cold-induced immune activity is linked to cold injury. Because hemocytes are

237 responsible for the phagocytosis of apoptotic and damaged cells (Marmaras and Lampropoulou,

238 2009) and increase in circulating concentration following tissue damage (Pastor-Pareja et al.,

239 2008), increased CHC following acute cold could represent a direct immune response to chilling

240 injury.

Although acute cold exposure increased some measures of potential immunity, flies also

243 displayed a reduced ability to clear gram-positive bacteria, B. subtilis, shortly after acute cold

244 exposure (2h). This contrast between potential and realised responses suggests that the increase

245 in CHC and AMPs is concomitant with impairment of the immune system. If chilling injury

246 includes damage to the hemocytes themselves, the circulating hemocytes we counted may

247 include both functional and damaged cells (Yi and Lee, 2003); thus although more cells appear

248 to be in circulation, immune function is either impaired or unchanged. Additionally, recovery

249 from chilling injury is metabolically costly (MacMillan et al., 2012), as are immune responses

250 (Freitak et al., 2003), and the initial decrease in bacterial clearance after acute cold could

251 represent a trade-off between recovery from cold exposure and immune activity. For example,

252 infected Drosophila take longer to recover from cold exposure (Linderman et al., 2012),

253 suggesting that there is a conflict between the response to cold and the response to infection. In

254 either the case of direct damage or trade-offs between immunity and recovery from cold, cold

255 exposure appears to have the potential to impair immune activity. 
Despite this initial impairment of immunity, activity appeared to have recovered by $6 \mathrm{~h}$ post cold exposure, we did not observe an impaired response to gram-negative E. coli, and nor was

259 there a change in survival of fungal infection. The immune response (including rate of

260 phagocytosis, the role of hemocytes, and the timing of expression of AMPs) varies depending on

261 the type of pathogen encountered (Lemaitre and Hoffmann, 2007; Marmaras and Lampropoulou, 262 2009), thus it is possible that the mechanism for clearing B. subtilis is more affected by chilling 263 injury than the mechanisms for responding to E. coli or M. anispoliae. Alternatively, up264 regulation of diptericin through the IMD pathway (largely responsible for the response to gram265 negative bacteria) may have compensated for impaired immunity and allowed the flies to 266 maintain clearance of gram-negative E. coli. Similarly, recovery of the response to B. subtilis 267 suggests that the immune response compensates for this initial, cold-induced impairment of 268 activity.

We propose that the increase in potential immunity that we observed following acute cold

271 exposure is a compensatory response to immune impairment through direct damage to the 272 immune system or trades-off with the response to cold. This compensatory response may 273 manifest as reconfiguration of the immune system (Adamo, 2014), that allows Drosophila to 274 maintain responses to cold-induced tissue damage or pathogens in the environment. Overall, this 275 suggests that cold-induced increases in immune activity are adaptive, and that it is important to 276 maintain the ability to respond to pathogens following cold exposure. It will next be important to 277 determine if conflicts between cold and immunity are present in other insect taxa, if they vary 
278 seasonally, and whether they affect the fitness of overwintering insects experiencing both cold

279 and pathogen stress.

281 In conclusion, we suggest that Drosophila have evolved immune activation by cold to

282 maintain the ability to respond to immune challenge to compensate for cold-induced damage to,

283 or trade-offs with, the immune system, but that this activation does not result in an increase in

284 realised activity. In the context of multiple stressors, this therefore demonstrates an evolved

285 resilience to the direct effect of an abiotic stressor on the ability to respond to pathogen stress,

286 and provides (another) warning about the importance of comparing multiple measures of the

287 immunity before drawing conclusions (Adamo, 2004).

\section{Acknowledgements}

290 Thanks to Drs. Jim Staples and Graham Thompson for equipment use, Ruth Jakobs and Calvin

291 Tsui for assistance in the laboratory, and Kurtis Turnbull and several anonymous reviewers for

292 comments that improved the ms. This work was supported by the Natural Sciences and

293 Engineering Research Council of Canada via a Discovery Grant to BJS and a Doctoral

294 scholarship to LVF. 


\section{References}

Adamo, S.A., 2004. Estimating disease resistance in insects: phenoloxidase and lysozyme-like activity and disease resistance in the cricket Gryllus texensis. Journal of Insect Physiology 50, 209-216.

Adamo, S.A., 2014. The effects of stress hormones on immune function may be vital for the adaptive reconfiguration of the immune system during fight-or-flight behavior. Integrative and Comparative Biology 54, 419-426.

Bidochka, M.J., Kasperski, J.E., Wild, G.A.M., 1998. Occurrence of the entomopathogenic fungi Metarhizium anisopliae and Beauveria bassiana in soils from temperate and near-northern habitats. Canadian Journal of Botany 76, 1198-1204.

Bing, X., Zhang, J., Sinclair, B.J., 2012. A comparison of Frost expression among species and life stages of Drosophila. Insect Molecular Biology 21, 31-39.

Carrington, L.B., Hoffmann, A., Weeks, A.R., 2010. Monitoring long-term evolutionary changes following Wolbachia introduction into a novel host: the Wolbachia popcorn infection in Drosophila simulans. Proceedings of the Royal Society B 277, 2059-2068.

Drobnis, E.Z., Crowe, L.M., Berger, T., Anchordoguy, T.J., Overstreet, J.W., Crowe, J.H., 1993. Cold shock damage is due to lipid phase transitions in cell membranes: A demonstration using sperm as a model. Journal of Experimental Zoology 265, 432-437.

Fedorka, K.M., Linder, J.E., Winterhalter, W., Promislow, D., 2007. Post-mating disparity between potential and realized immune response in Drosophila melanogaster. Proceedings of the Royal Society B 274, 1211-1217.

Freitak, D., Ots, I., Vanatoa, A., Horak, P., 2003. Immune response is energetically costly in white cabbage butterfly pupae. Proceedings of the Royal Society B 270 Suppl 2, S220-222.

Kaunisto, S., Ferguson, L.V., Sinclair, B.J., 2016. Can we predict the effects of multiple stressors on insects in a changing climate? Current Opinion in Insect Science 17, 55-61.

Le Bourg, E., Massou, I., Gobert, V., 2009. Cold stress increases resistance to fungal infection throughout life in Drosophila melanogaster. Biogerontology 10, 613-625.

Lee, R.E., Damodaran, K., Yi, S.X., Lorigan, G.A., 2006. Rapid cold-hardening increases membrane fluidity and cold tolerance of insect cells. Cryobiology 52, 459-463.

Lemaitre, B., Hoffmann, J., 2007. The host defense of Drosophila melanogaster. Annual Review of Immunology 25, 697-743.

Linderman, J.A., Chambers, M.C., Gupta, A.S., Schneider, D.S., 2012. Infection-related declines in chill coma recovery and negative geotaxis in Drosophila melanogaster. PloS One 7, e41907.

MacMillan, H.A., Ferguson, L.V., Nicolai, A., Donini, A., Staples, J.F., Sinclair, B.J., 2015. Parallel ionoregulatory adjustments underlie phenotypic plasticity and evolution of Drosophila cold tolerance. Journal of Experimental Biology 218, 423-432.

MacMillan, H.A., Hughson, B.N., 2014. A high-throughput method of hemolymph extraction from adult Drosophila without anesthesia. Journal of Insect Physiology 63, 27-31.

MacMillan, H.A., Williams, C.M., Staples, J.F., Sinclair, B.J., 2012. Reestablishment of ion homeostasis during chill-coma recovery in the cricket Gryllus pennsylvanicus. Proceedings of the National Academy of Sciences USA 109, 20750-20755.

Maltzinger, P., 1998. An innate sense of danger. Seminars in immunology 10, 399-415.

Marmaras, V.J., Lampropoulou, M., 2009. Regulators and signalling in insect haemocyte immunity. Cellular Signalling 21, 186-195. 
Marshall, K.E., Sinclair, B.J., 2010. Repeated stress exposure results in a survival-reproduction trade-off in Drosophila melanogaster. Proceedings of the Royal Society B 277, 963-969.

Marshall, K.E., Sinclair, B.J., 2011. The sub-lethal effects of repeated freezing in the woolly bear caterpillar Pyrrharctia isabella. Journal of Experimental Biology 214, 1205-1212.

McKean, K.A., Nunney, L., 2001. Increased sexual activity reduces male immune function in Drosophila melanogaster. Proceedings of the National Academy of Sciences USA 98, 7904-7909.

Nilson, T.N., Sinclair, B.J., Roberts, S.P., 2006. The effects of carbon dioxide anesthesia and anoxia on rapid cold-hardening and chill coma recovery in Drosophila melanogaster. J Insect Physiol 52, 1027-1033.

Nyamukondiwa, C., Terblanche, J.S., Marshall, K.E., Sinclair, B.J., 2011. Basal cold but not heat tolerance constrains plasticity among Drosophila species (Diptera: Drosophilidae). Journal of Evolutionary Biology 24, 1927-1938.

Pastor-Pareja, J.C., Wu, M., Xu, T., 2008. An innate immune response of blood cells to tumors and tissue damage in Drosophila. Disease Models and Mechanisms 1, 144-154.

R Development Core Team, 2010. R: A language and environment for statistical computing. $\mathrm{R}$ Foundation for Statistical Computing, Vienna, Austria.

Sinclair, B.J., Ferguson, L.V., Salehipour-shirazi, G., MacMillan, H.A., 2013. Cross-tolerance and cross-talk in the cold: relating low temperatures to desiccation and immune stress in insects. Integrative and Comparative Biology 53, 545-556.

Williams, C.M., Henry, H.A., Sinclair, B.J., 2015. Cold truths: how winter drives responses of terrestrial organisms to climate change. Biological Reviews 90, 214-235.

Yi, S.-X., Lee, R.E., 2003. Detecting freeze injury and seasonal cold-hardening of cells and tissues in the gall fly larvae, Eurosta solidaginis (Diptera: Tephritidae) using fluorescent vital dyes. Journal of Insect Physiology 49, 999-1004.

Yi, S.X., Moore, C.W., Lee, R.E., Jr., 2007. Rapid cold-hardening protects Drosophila melanogaster from cold-induced apoptosis. Apoptosis 12, 1183-1193.

Zachariassen, K.E., 1985. Physiology of cold tolerance in insects. Physiological Reviews 65, 799-832.

Zhang, J., Marshall, K.E., Westwood, J.T., Clark, M.S., Sinclair, B.J., 2011. Divergent transcriptomic responses to repeated and single cold exposures in Drosophila melanogaster. Journal of Experimental Biology 214, 4021-4029. 
Figure Legends

Figure 1. Circulating haemocyte concentration of Drosophila melanogaster following cold exposure. Flies were exposed to acute $\left(-2{ }^{\circ} \mathrm{C}, 2 \mathrm{~h}\right)$ or sustained $\left(-0.5^{\circ} \mathrm{C}, 10 \mathrm{~h}\right) \mathrm{cold}$; $\mathrm{n}=10$ per treatment. Mean \pm SEM is shown; asterisks indicate significant differences $(p<0.05)$ between cold-exposed and control flies (see Table 1 for statistics).

Figure 2. Haemolymph phenoloxidase activity of Drosophila melanogaster following cold exposure. Flies were exposed to acute $\left(-2{ }^{\circ} \mathrm{C}, 2 \mathrm{~h}\right)$ or sustained $\left(-0.5^{\circ} \mathrm{C}, 10 \mathrm{~h}\right)$ cold; $\mathrm{n}=3-5$ per treatment (8-10 flies pooled per replicate). Mean \pm SEM is shown.

Figure 3. Relative mRNA abundance of genes related to Drosophila melanogaster immune pathways measured by real-time qPCR, following cold exposure. Flies were exposed to acute $\left(-2{ }^{\circ} \mathrm{C}, 2 \mathrm{~h}\right)$ or sustained $\left(-0.5^{\circ} \mathrm{C}, 10 \mathrm{~h}\right)$ cold; $\mathrm{n}=5 /$ gene/treatment (30 flies pooled per replicate) dros $=$ drosomycin, def=defensin, mtk=metchnikowin, atta =attacin, cec $=$ cecropin, dipt $=$ diptericin, $d r o=d r o s o c i n$, Tot $A=$ Turandot $A$ and vir $=$ vir-1. Mean \pm SEM is shown; asterisks indicate significant differences $(\mathrm{p}<0.05)$ between cold-exposed and control flies; sustained cold (see Table 1 for statistics).

Figure 4. Survival of cold-exposed Drosophila melanogaster infected with Metarhizium anisopliae (n=8-10 flies in 5-7 vials/treatment). Flies were exposed to acute $\left(-2{ }^{\circ} \mathrm{C}, 2 \mathrm{~h}\right)$ or sustained $\left(-0.5^{\circ} \mathrm{C}, 10 \mathrm{~h}\right)$ cold and topically infected with $M$. anispoliae following recovery from cold. Mean \pm SEM is shown (see Table 1 for statistics). 
401 Figure 5. Wounding response in Drosophila melanogaster measured as cuticle melanisation

402 (grey value) following cold exposure. Flies were exposed to acute $\left(-2^{\circ} \mathrm{C}, 2 \mathrm{~h}\right)$ or sustained ($4030.5^{\circ} \mathrm{C}, 10 \mathrm{~h}$ ) cold and pierced in the thorax with an insect pin following recovery from cold. $\mathrm{n}=$ 40410 per treatment, per time point (see Table 1 for statistics).

405

406

Figure 6. In vivo clearance of Escherichia coli and Bacillus subtilis from the hemolymph of

407 Drosophila melanogaster following cold exposure. Flies were exposed to acute $\left(-2{ }^{\circ} \mathrm{C}, 2 \mathrm{~h}\right)$ or 408 sustained $\left(-0.5^{\circ} \mathrm{C}, 10 \mathrm{~h}\right)$ cold and injected with a suspension of bacteria $2 \mathrm{~h}$ or $6 \mathrm{~h}$ following 409 recovery from cold. The proportion of bacteria cleared from the hemolymph was assessed either $4105 \mathrm{~h}$ or $12 \mathrm{~h}$ following injection; ( $\mathrm{n}=4-9 /$ treatment/infection). Lower-case letters indicate

411 significant differences $(\mathrm{p}<0.05)$ between acute cold-exposed, sustained cold-exposed, and control 412 flies (see Table 1 for statistics). 
417 Table 1. Effects of acute $\left(2 \mathrm{~h},-2^{\circ} \mathrm{C}\right)$ or sustained $\left(10 \mathrm{~h},-0.5^{\circ} \mathrm{C}\right)$ cold exposure on potential and realised immunity of female

418 Drosophila melanogaster. Cold refers to both acute and sustained exposures, compared to controls. P-values in bold indicate

419 significant differences. $\mathrm{PC}=$ post-cold exposure; $\mathrm{PI}=$ post-infection

\begin{tabular}{llll} 
Measure & Term(s) & Statistic & p \\
\hline Potential immunity & & & \\
\hline Circulating haemocyte counts & Acute vs control & $\mathrm{t}_{15}=3.51$ & $<\mathbf{0 5}$ \\
& Sustained vs control & $\mathrm{t}_{16}=0.87$ & 0.39 \\
\hline mRNA abundance & Acute vs control (diptericin) & $\mathrm{t}_{4}=7.10$ & $<\mathbf{0 . 0 1}$ \\
& Acute vs control (Turandot - A) & $\mathrm{t}_{4}=3.43$ & $<\mathbf{0 . 0 0 1}$ \\
& Sustained vs control (Turandot- A) & $\mathrm{t}_{4}=11.95$ & $<\mathbf{0 . 0 0 1}$ \\
& Acute vs sustained (Metchnikowin) & $\mathrm{t}_{4}=8.54$ & $\mathbf{0 . 0 4 6}$ \\
\hline Realised immunity & & & \\
\hline Fungal infection & Infected vs uninfected & $\mathrm{t}_{252}=34.37$ & $<\mathbf{0 . 0 0 1}$ \\
& Acute vs control & $\mathrm{t}_{14}=1.17$ & 0.26 \\
& Sustained vs control & $\mathrm{t}_{14}=1.72$ & 0.11 \\
\hline Melanisation & Acute vs control & $\mathrm{t}_{90}=1.76$ & 0.08 \\
& Sustained vs control & $\mathrm{t}_{90}=1.21$ & 0.23 \\
\hline Bacterial clearance & & & \\
2 h PC; 5 h PI & & $\mathrm{F}_{2,23}=9.10$ & $<\mathbf{0 . 0 1}$ \\
& Treatment & $\mathrm{F}_{1,23}=13.26$ & $<\mathbf{0 . 0 0 1}$ \\
& Bacteria & $\mathrm{F}_{2,23}=3.37$ & 0.067 \\
6 h PC, 5 h PI & Treatment $\times$ Bacteria & $\mathrm{F}_{2,22}=0.50$ & 0.61 \\
& Treatment & $\mathrm{F}_{1,22}=7.82$ & $\mathbf{0 . 0 1}$ \\
& Bacteria & $\mathrm{F}_{2,22}=0.93$ & 0.93 \\
6 h PC; 12 h PI & Treatment $\times$ Bacteria & $\mathrm{F}_{2,17}=0.89$ & 0.92 \\
& Treatment & $\mathrm{F}_{1,17}=0.511$ & $\mathbf{0 . 0 3}$ \\
& Bacteria & $\mathrm{F}_{2,17}=0.892$ & 0.43 \\
\hline
\end{tabular}


423 Figure 1

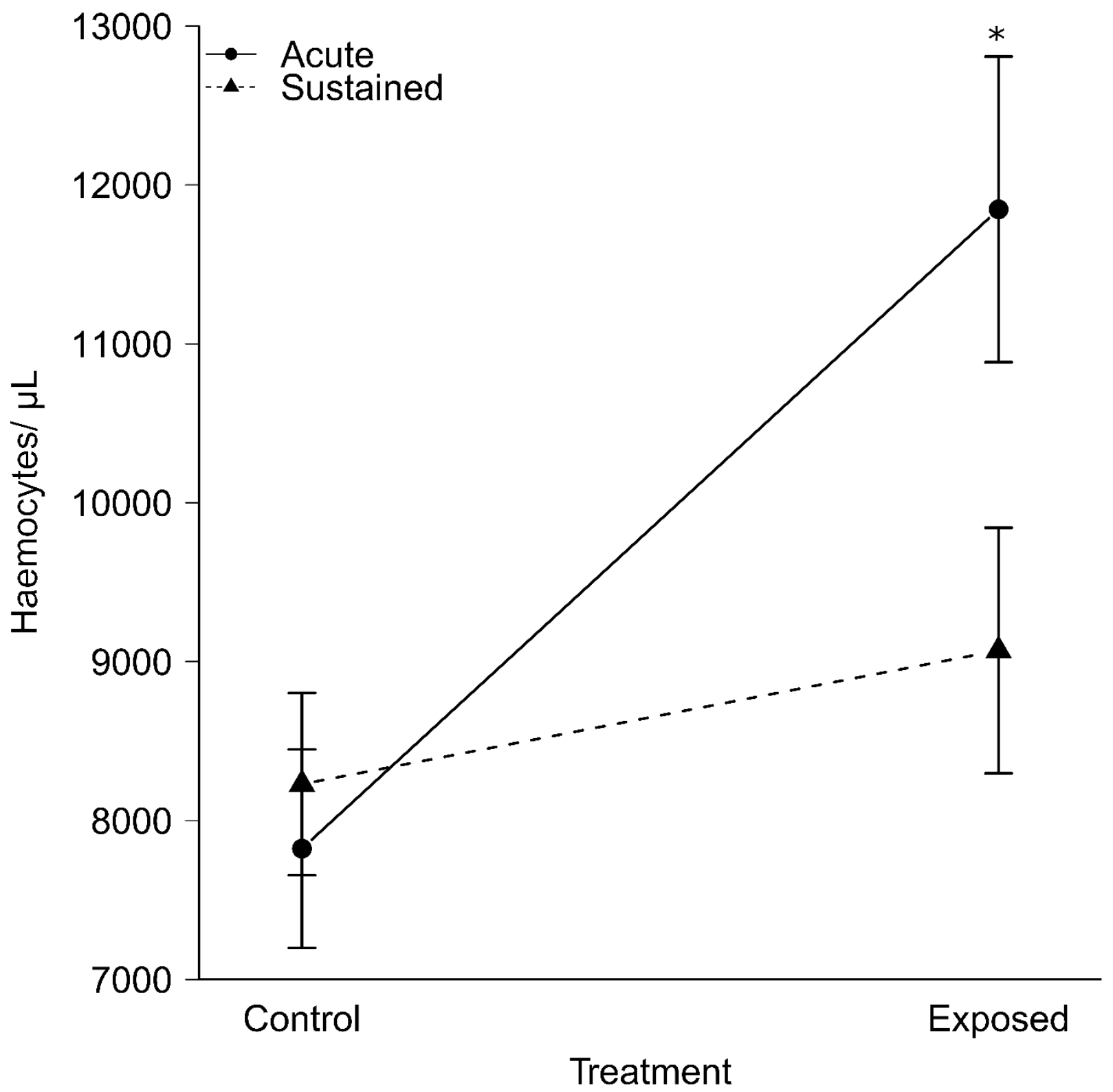


426 Figure 2

427

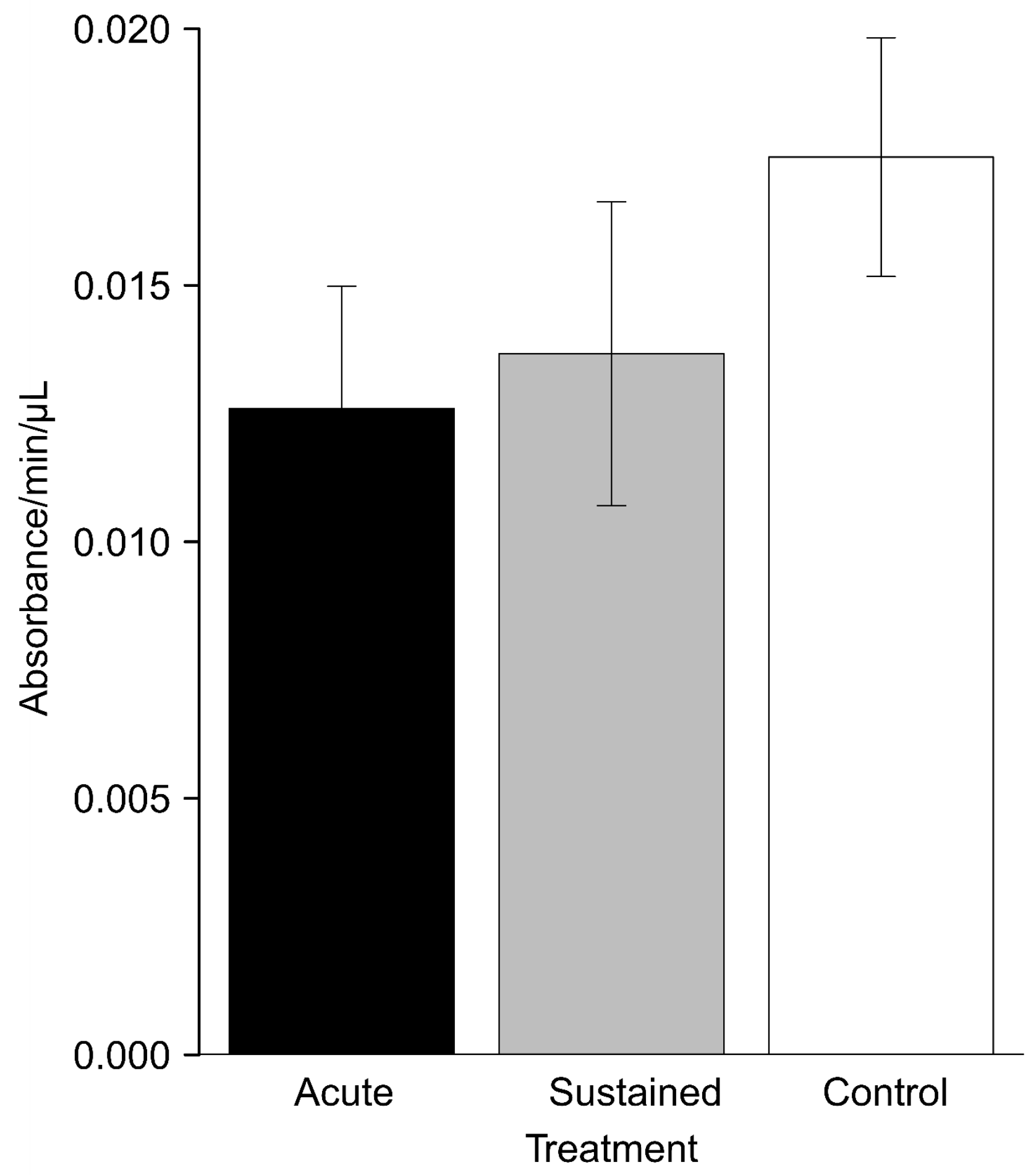




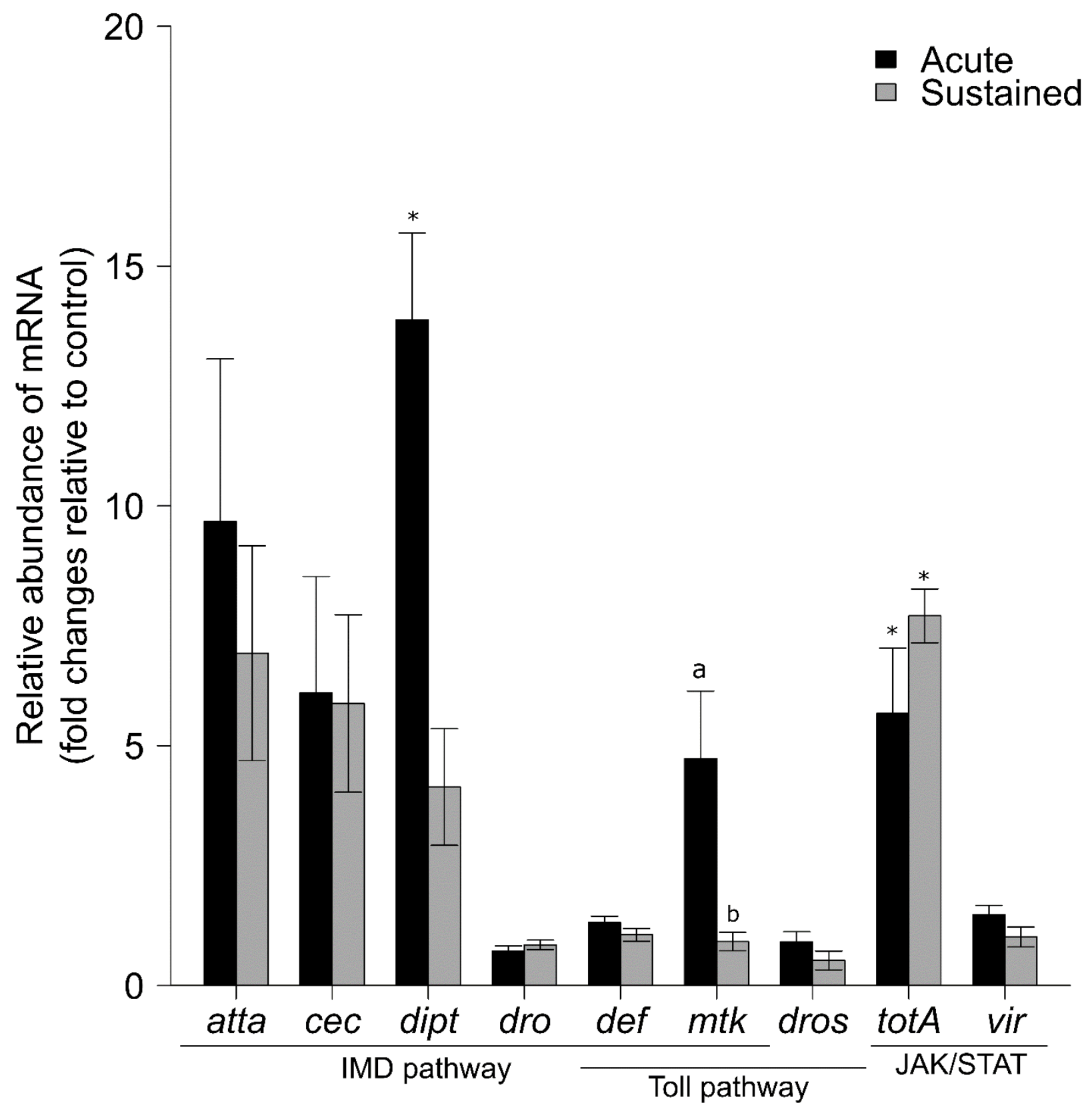




\section{Figure 4}

434

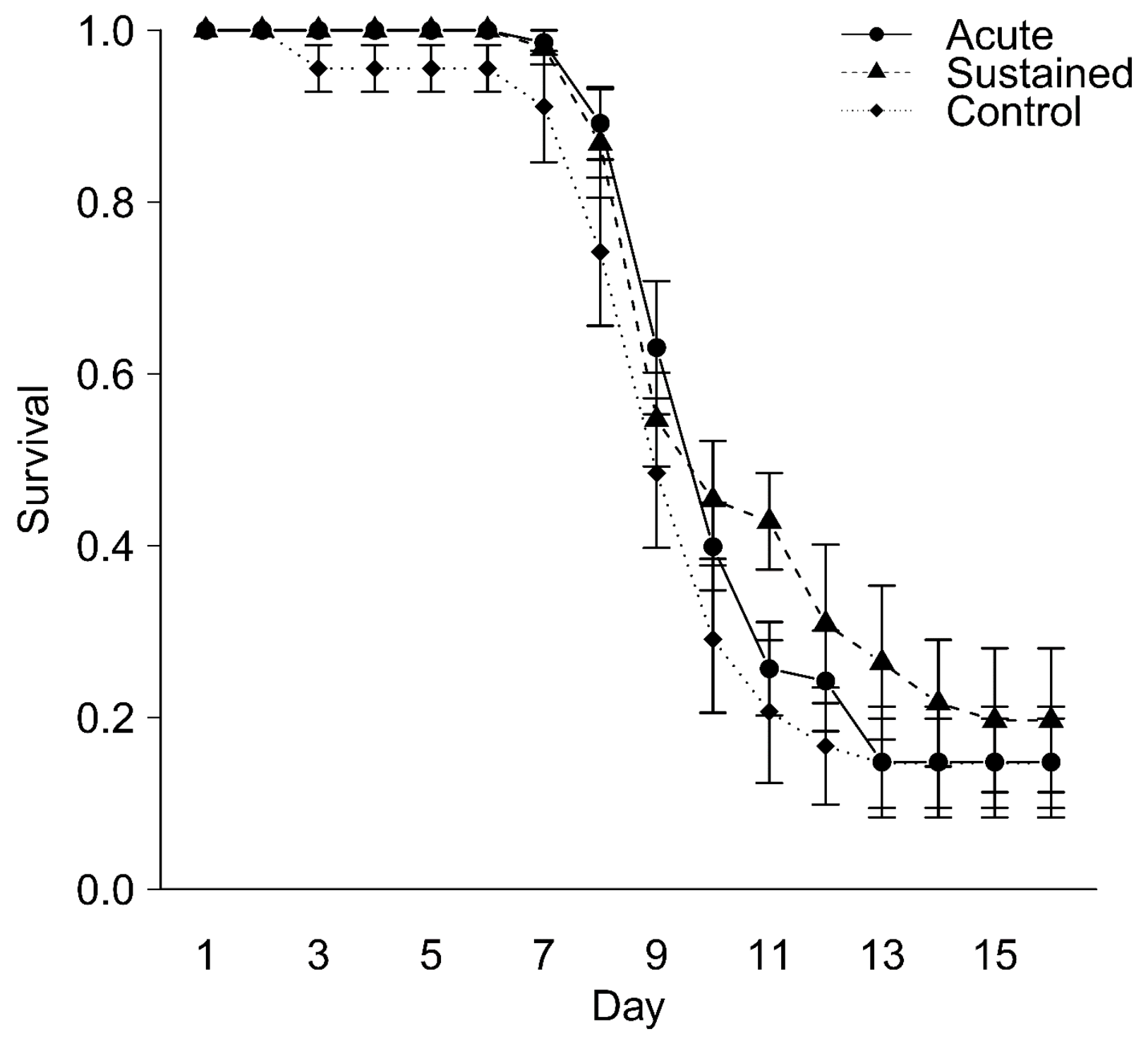


437 Figure 5

438

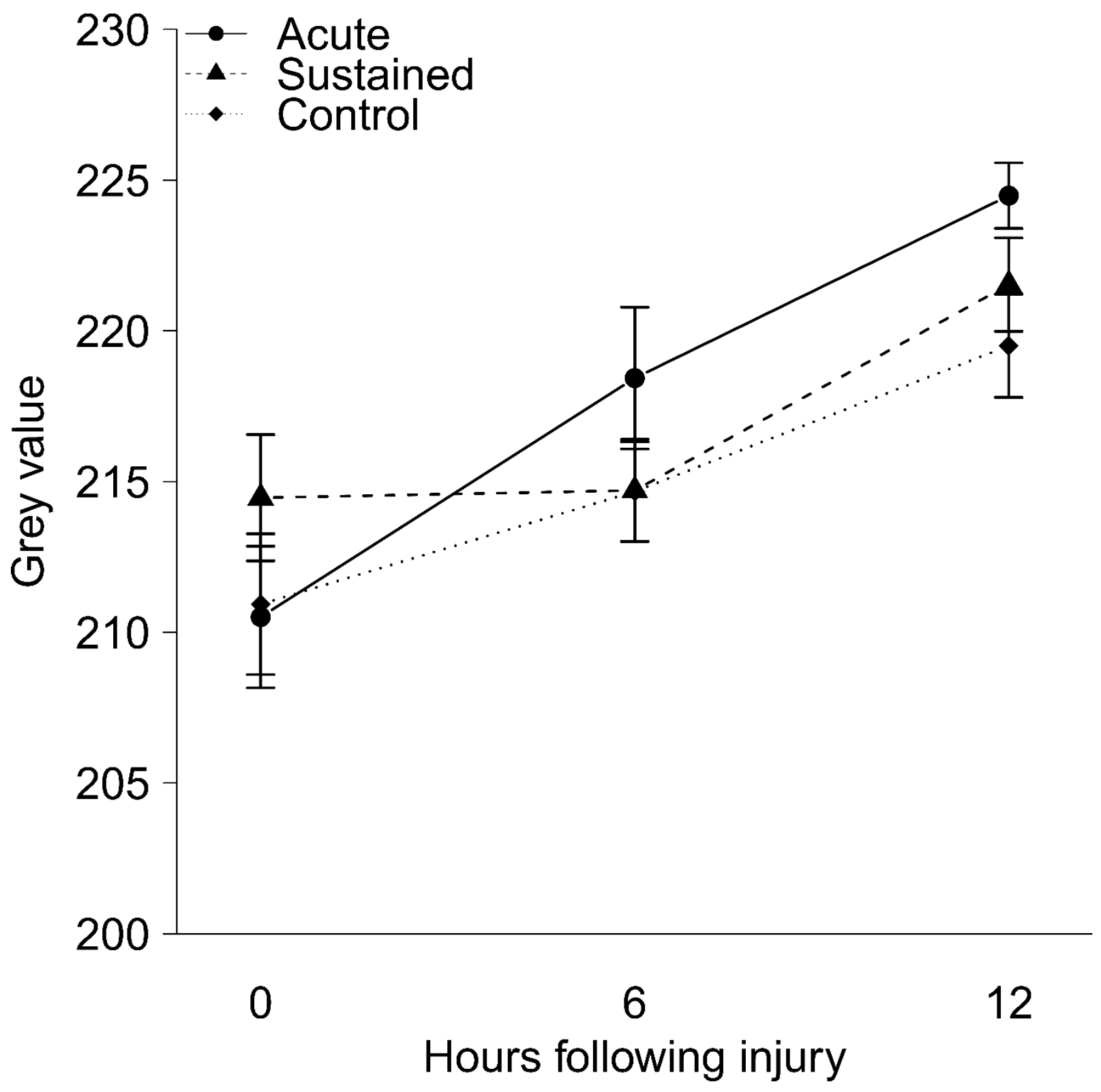




\section{$441 \quad$ Figure 6}

442

A: $2 \mathrm{~h}$ post-cold, $5 \mathrm{~h}$ post-injection

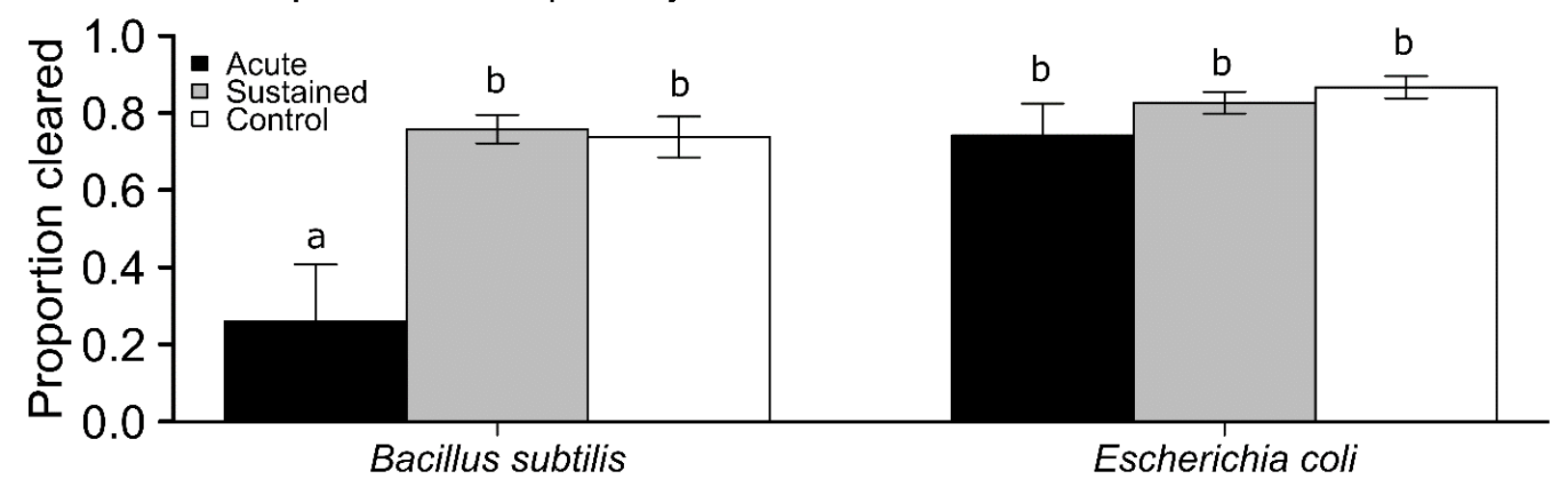

B: $6 \mathrm{~h}$ post-cold, $5 \mathrm{~h}$ post-injection

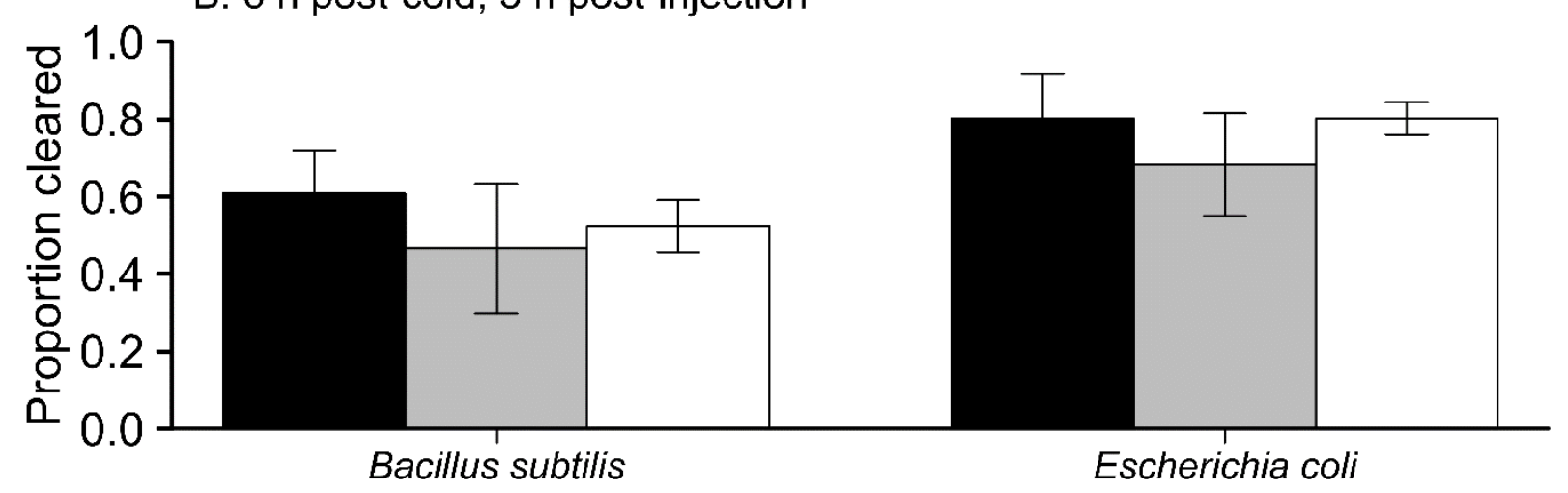

C: $6 \mathrm{~h}$ post-cold, $12 \mathrm{~h}$ post-injection

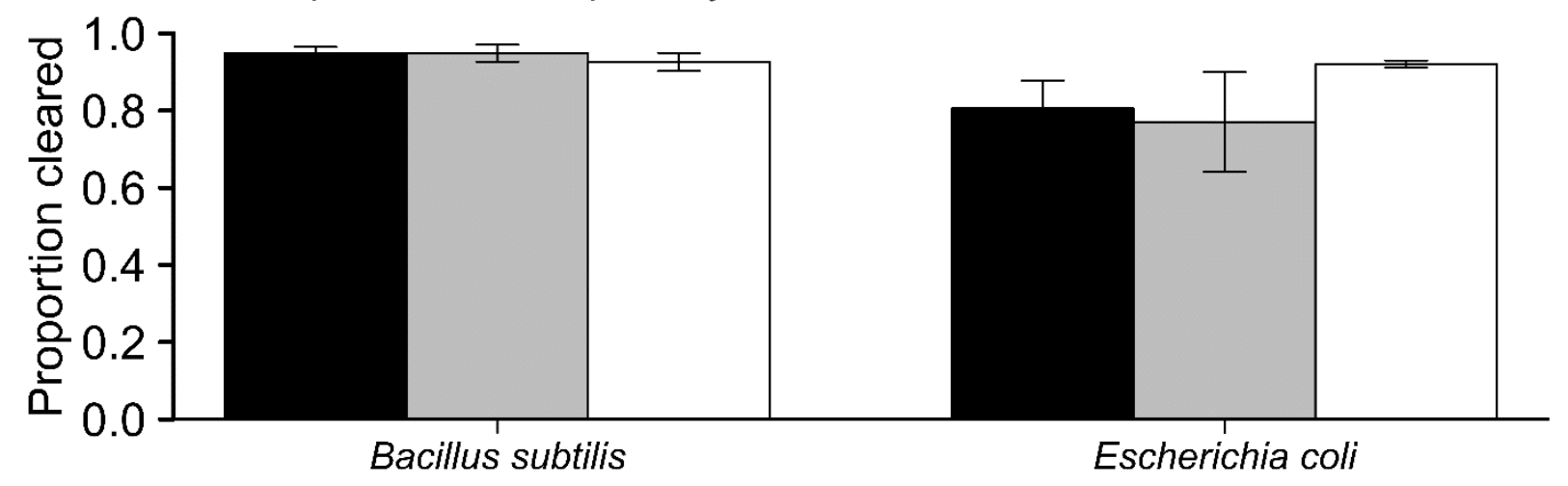




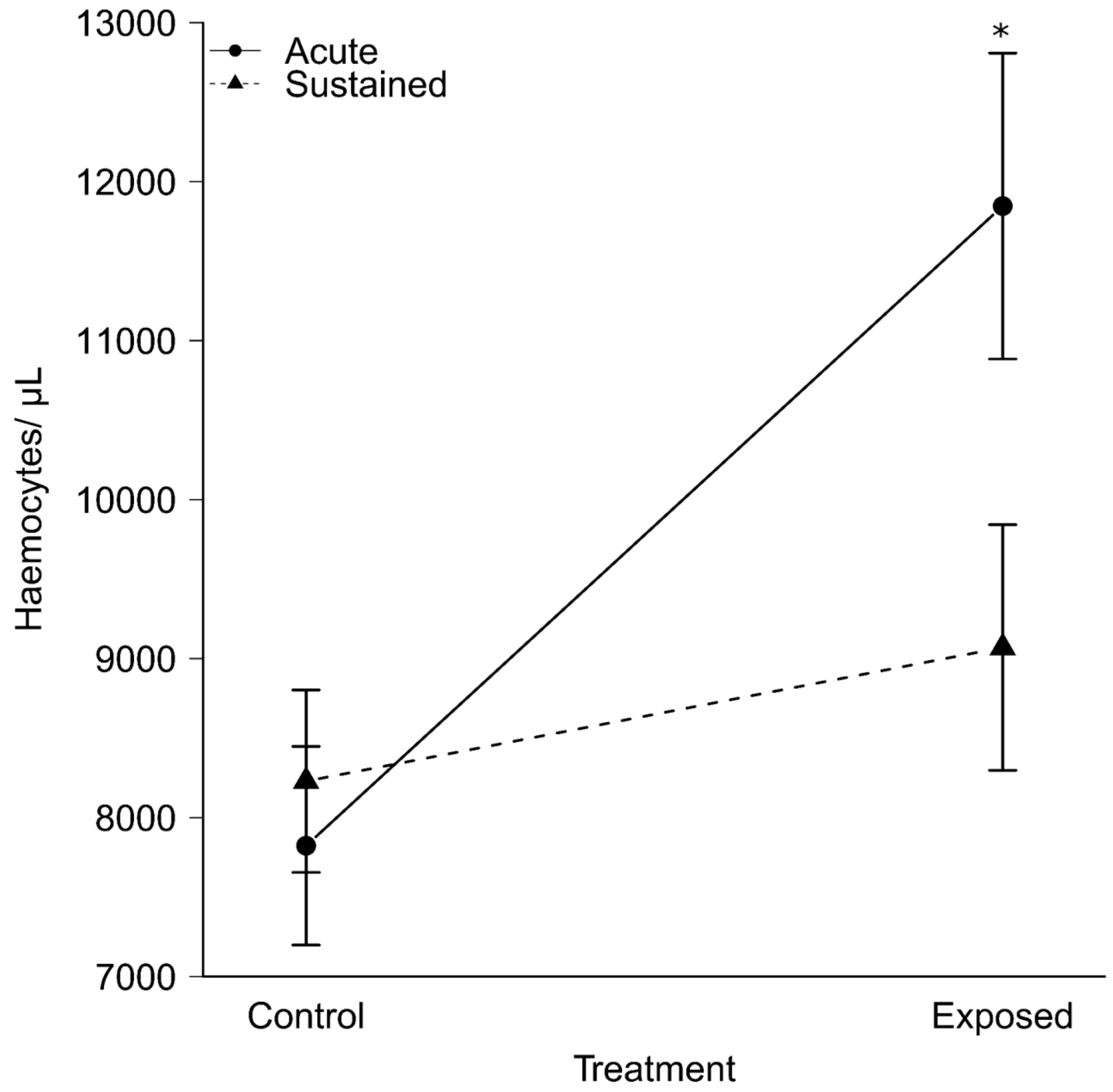




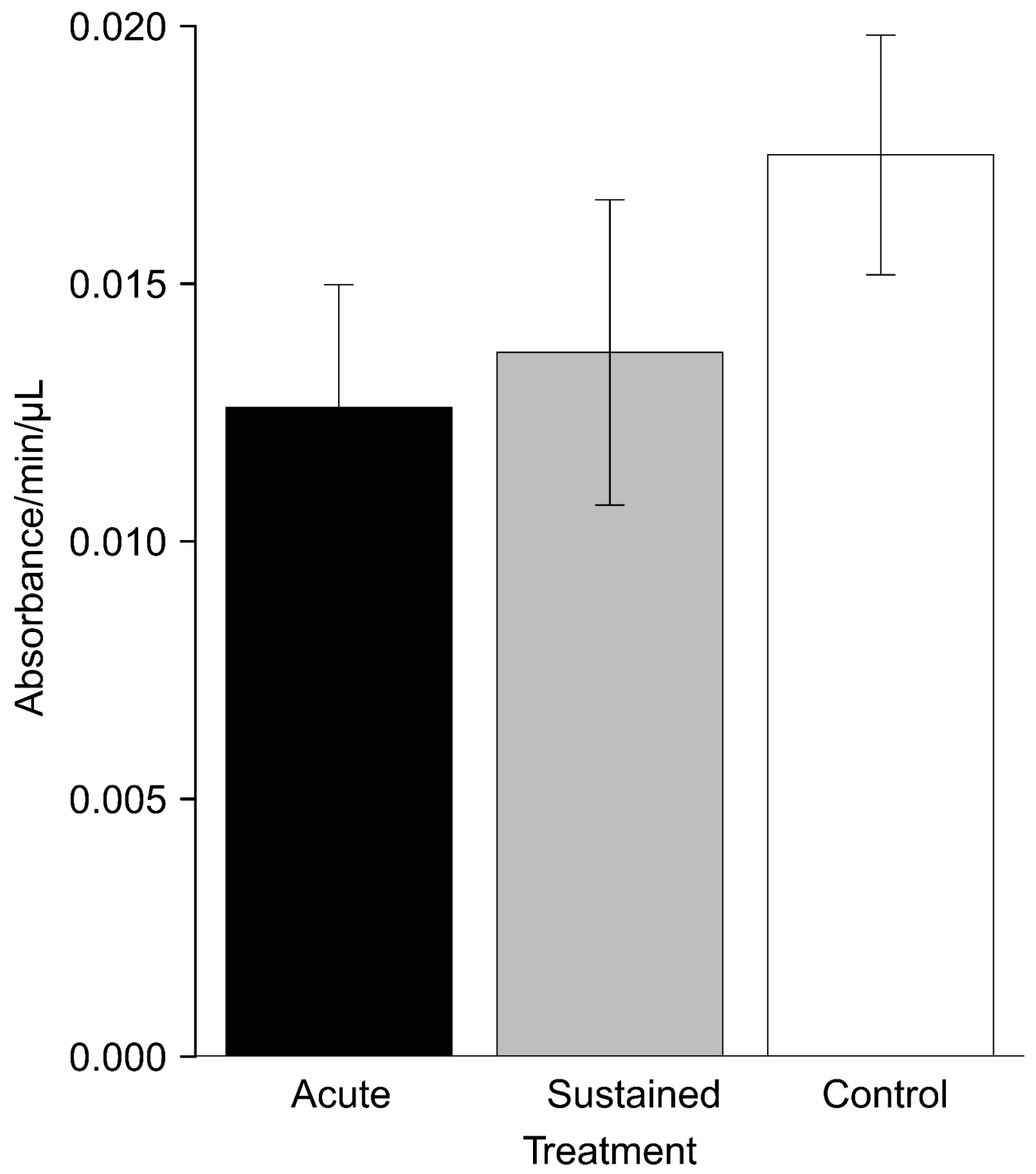




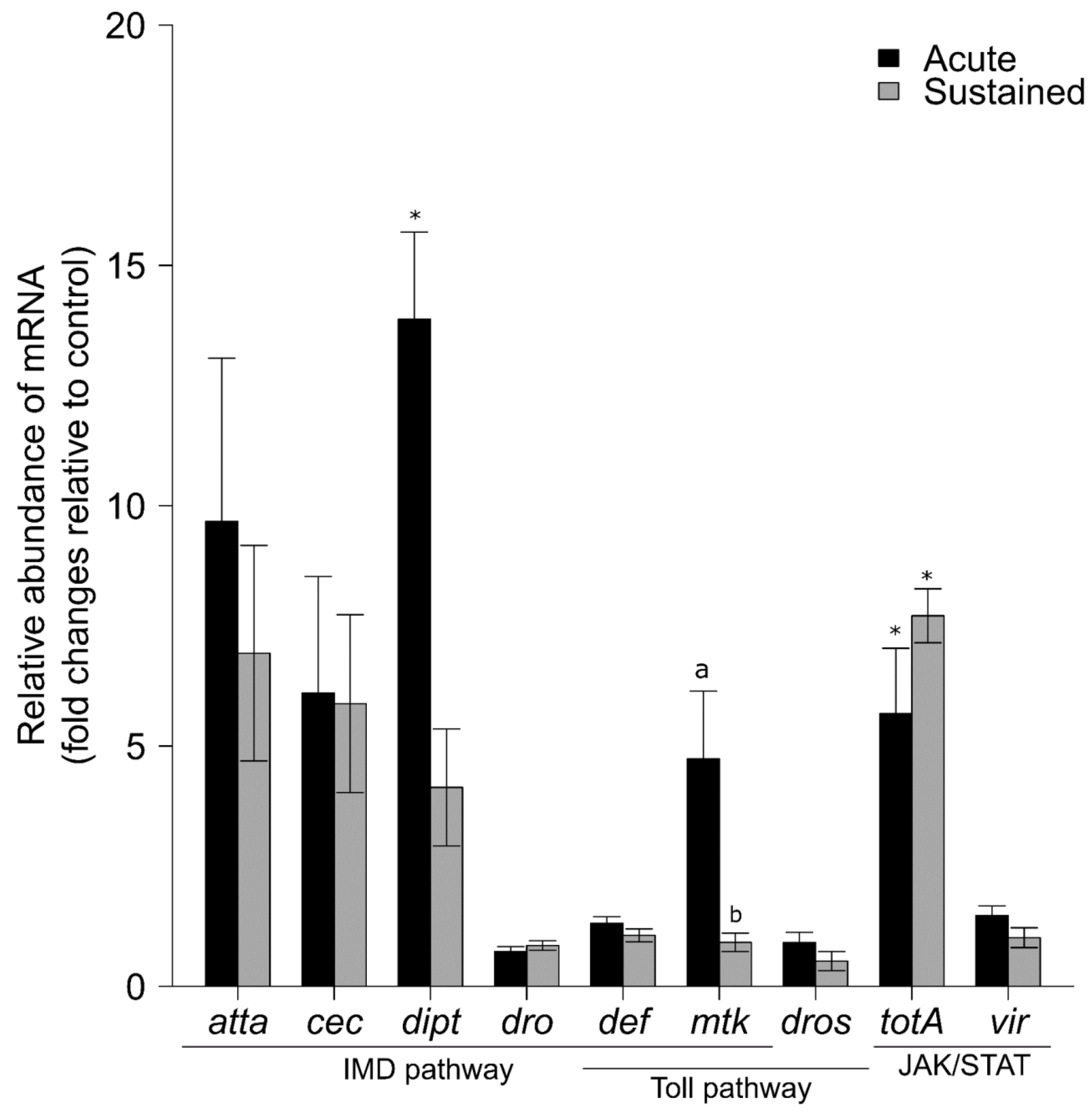




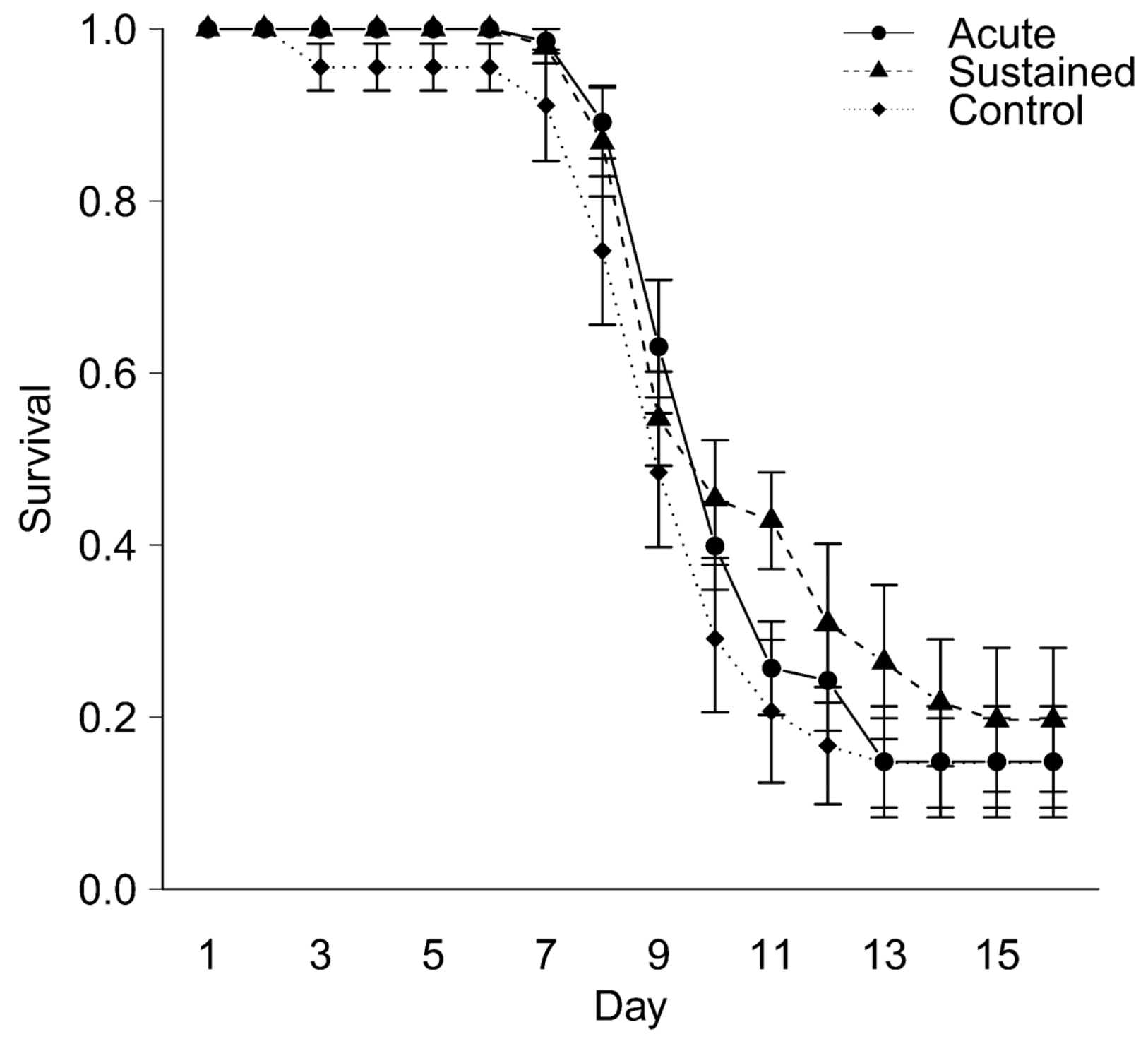




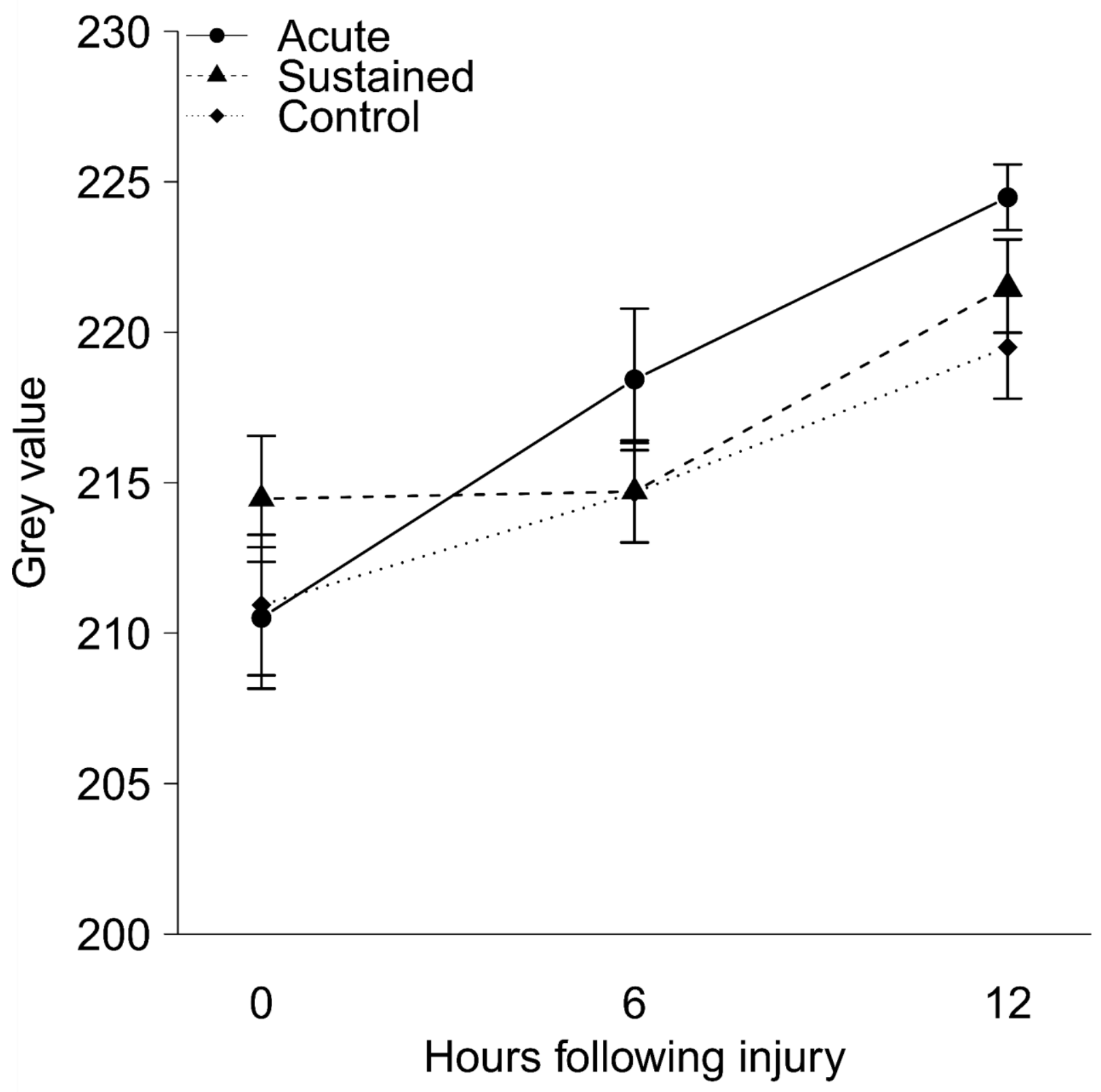



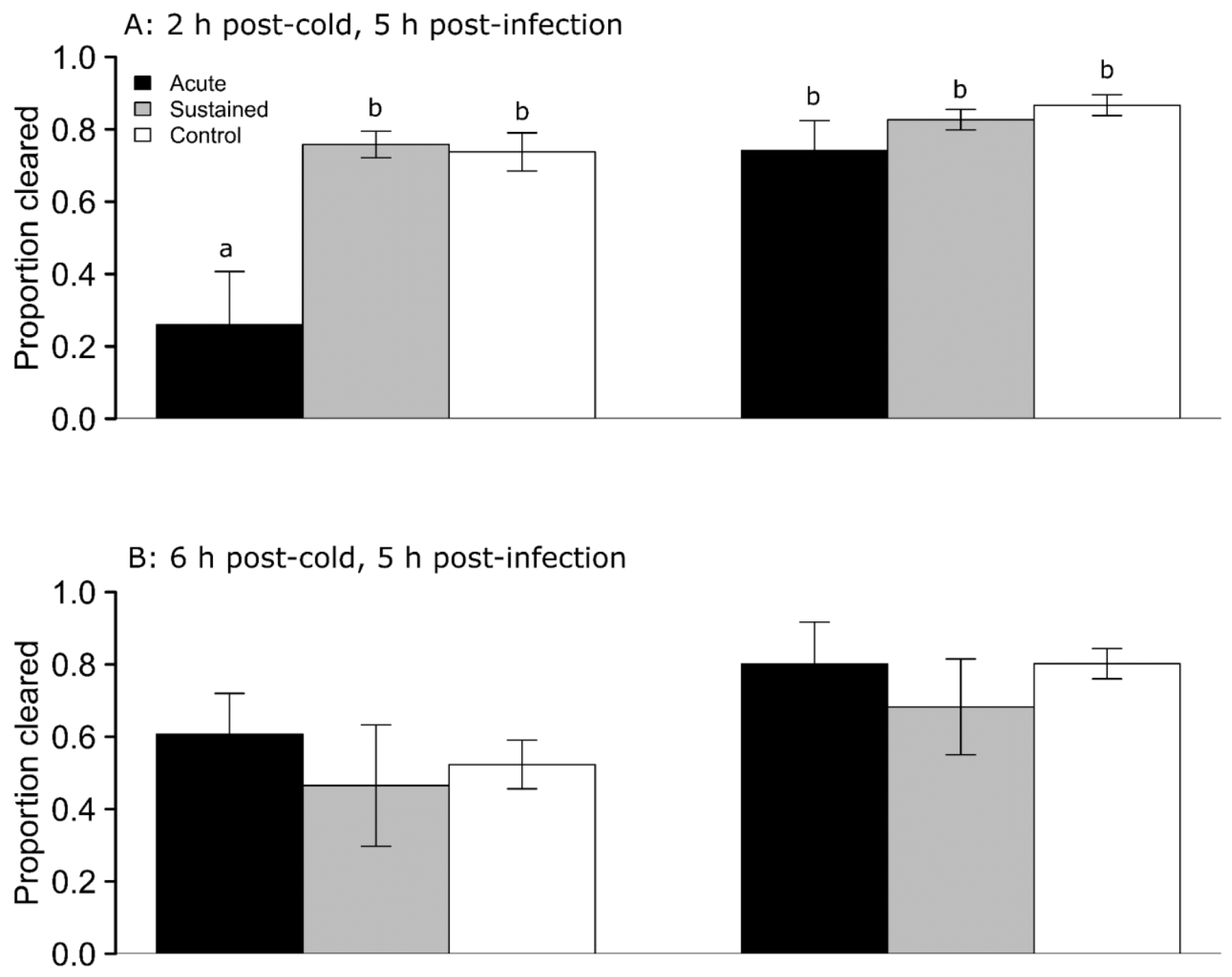

C: $6 \mathrm{~h}$ post-cold, $12 \mathrm{~h}$ post-infection

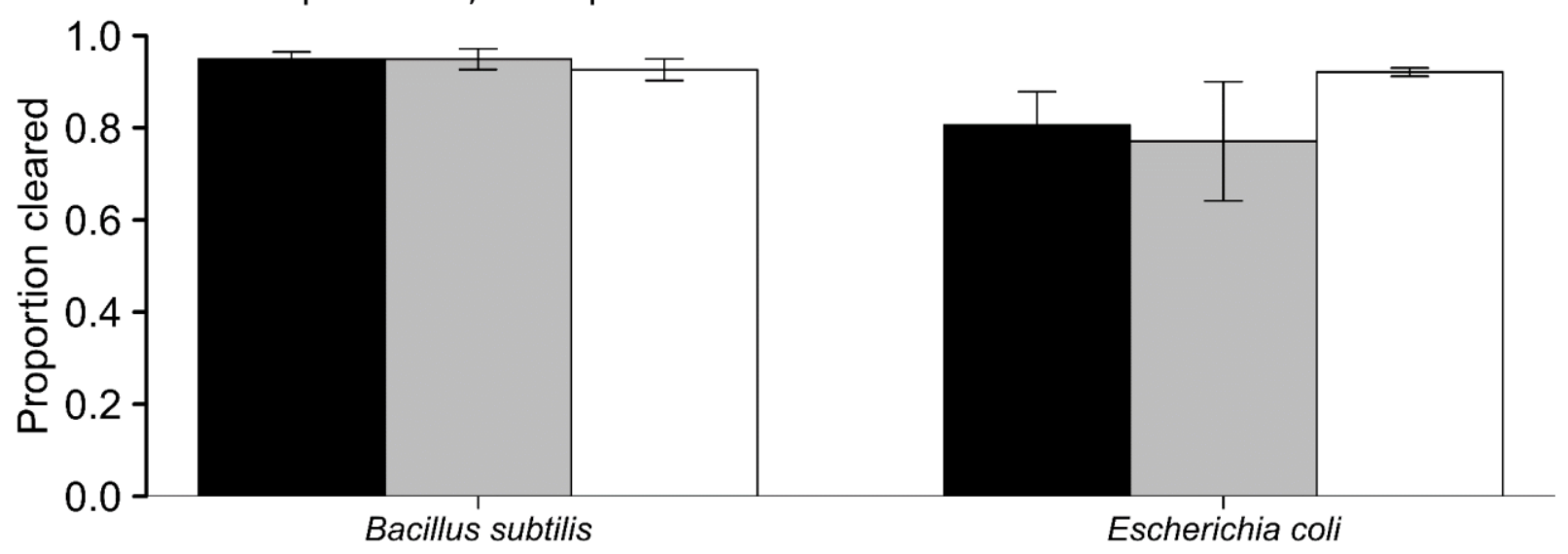




\section{Supplemental methods and results}

Table S1: Primers used to measure expression of genes related to Toll, IMD, and

Jak/STAT pathways in Drosophila melanogaster using q-PCR. The reference gene is Rpl32.

$\mathrm{T}_{\mathrm{m}}$ indicates the melting temperature. References are noted for primers derived from literature.

When designed in-house, Primer3 was used to design primers with amplicons of less than 250 bp long and GC content of 45-65\% with no self-complementarity. Amplification efficiency of the primers was checked to be more than 95\% using calibration curves of serially diluted concentration of the primers and the specificity of the primers was verified by PCR.

\begin{tabular}{|c|c|c|c|}
\hline Gene & Nucleotide sequence (5’ to 3’) & $\mathbf{T}_{\mathbf{m}}$ & Reference \\
\hline \multirow[t]{2}{*}{ Rpl32 } & 5'-GACGCTTCAAGGGACAGTATCTG-3’ & 62 & [1] \\
\hline & 5'-AAACGCGGTTCTGCATGAG-3' & 62 & \\
\hline \multirow[t]{2}{*}{ attacin- $B$} & 5’-GGCCCATGCCAATTTATTCA-3' & 63 & {$[2]$} \\
\hline & 5’-CATTGCGCTGGAACTCGAA-3’ & 63 & \\
\hline \multirow[t]{2}{*}{ cecropin-A } & 5’-TCTTCGTTTTCGTCGCTCTC-3’ & 61 & {$[2]$} \\
\hline & 5'-CTTGTTGAGCGATTCCCAGT-3' & 60 & \\
\hline \multirow{2}{*}{ defensin } & 5’-GCCAGAAGCGAGCCACAT-3’' & 63 & [2] \\
\hline & 5’-CGGTGTGGTTCCAGTTCCA-3’ & 63 & \\
\hline \multirow[t]{2}{*}{ diptericin- $A$} & 5’-AGGTGTGGACCAGCGACAA-3' & 63 & [2] \\
\hline & 5’-TGCTGTCCATATCCTCCATTCA-3’ & 63 & \\
\hline \multirow[t]{2}{*}{ drosocin } & 5’-CCACCACTCCAAGCACAATG-3’ & 60 & \\
\hline & 5’-TGAGTCAGGTGATCCTCGATGG-3' & 58 & \\
\hline \multirow[t]{2}{*}{ drosomycin-B } & 5’-CTCCGTGAGAACCTTTTCCA-3’ & 60 & [2] \\
\hline & 5’-GTATCTTCCGGACAGGCAGT-3' & 59 & \\
\hline \multirow[t]{2}{*}{ metchnikowin } & 5'- CTACATCAGTGCTGGCAGAG-3' & 60 & \\
\hline & 5’- CGGTCTTGGTTGGTTAGGATTG-3’ & 58 & \\
\hline \multirow[t]{2}{*}{$P G R P-L B$} & 5’-TGTGGCCGCTTTAGTGCTT-3’' & 62 & {$[2]$} \\
\hline & 5’-TCAATCTGCAGGGCATTGG-3' & 63 & \\
\hline \multirow[t]{2}{*}{$P G R P-L C$} & 5'-ACGGAATCCAAGCGTATCAG-3' & 60 & [2] \\
\hline & 5'-GGCCTCCGAATCACTATCAA-3' & 60 & \\
\hline \multirow[t]{2}{*}{ PGRP-SB } & 5'-CTGCGGCTGTTATCAGTGAA-3' & 60 & {$[2]$} \\
\hline & 5’-TGATGGAATTTCCGCTTTTC-3’ & 60 & \\
\hline \multirow[t]{2}{*}{$P G R P-S D$} & 5’-CCTTGCCACGTGCTGTGA-3’ & 63 & {$[2]$} \\
\hline & 5'-TGTAACATCATCCGCACAAGCT-3' & 63 & \\
\hline \multirow[t]{3}{*}{ relish } & 5’-GTGGAGTTGGACCTAAGTAGTGG- & 55 & \\
\hline & 3 & 59 & \\
\hline & 5'- TGATTCAGCAGCGAACAGAGC-3' & & \\
\hline \multirow[t]{2}{*}{ toll } & 5’-AACTTGGGCAACCTTGTGAC-3’ & 60 & {$[2]$} \\
\hline & 5'-GTAACCAAACGGGGAGTTGA-3' & 60 & \\
\hline \multirow[t]{2}{*}{ TotA-1 } & 5’-TGAGGAACGGGAGAGTATCG-3’ & 60 & {$[2]$} \\
\hline & 5’-GCCCTTCACACCTGGAGATA-3' & 60 & \\
\hline \multirow[t]{2}{*}{ vir-1 } & 5’-TGTGCCCATTGACCTATCCA-3’ & 62 & [2] \\
\hline & 5’-GATTACAGCTGGGTGCACAA-3' & 60 & \\
\hline
\end{tabular}


Table S2. Statistical analyses of the effect of acute and chronic cold on expression level of immune genes of Drosophila melanogaster females. The data shows the relative abundance of the immune genes mRNA (normalized to Rpl-32) after acute cold exposure $\left(2 \mathrm{~h},-2{ }^{\circ} \mathrm{C}\right)$ and chronic cold exposure $\left(10 \mathrm{~h},-0.5^{\circ} \mathrm{C}\right)$.

\begin{tabular}{|c|c|c|c|c|}
\hline Gene & Treatment & Test value & $P$-value & Adjusted $P$ \\
\hline \multirow[t]{2}{*}{ attacin-B } & Acute & 2.56 & 0.063 & 0.13 \\
\hline & Chronic & 2.65 & 0.057 & 0.13 \\
\hline \multirow[t]{2}{*}{ cecropin-A } & Acute & 2.11 & 0.102 & 0.13 \\
\hline & Chronic & 2.64 & 0.058 & 0.14 \\
\hline \multirow[t]{2}{*}{ defensin } & Acute & 2.35 & 0.078 & 0.13 \\
\hline & Chronic & 0.46 & 0.67 & 0.75 \\
\hline \multirow[t]{2}{*}{ diptericin-A } & Acute & 7.10 & $<0.01$ & 0.09 \\
\hline & Chronic & 2.578 & 0.061 & 0.13 \\
\hline \multirow[t]{2}{*}{ drosocin } & Acute & 2.66 & 0.056 & 0.13 \\
\hline & Chronic & 1.66 & 0.172 & 0.22 \\
\hline \multirow[t]{2}{*}{ drosomycin-B } & Acute & 0.41 & 0.701 & 0.75 \\
\hline & Chronic & 2.42 & 0.072 & 0.13 \\
\hline \multirow[t]{2}{*}{ metchnikowin } & Acute & 2.66 & 0.046 & 0.13 \\
\hline & Chronic & 0.33 & 0.756 & 0.76 \\
\hline \multirow[t]{2}{*}{$P G R P-L B$} & Acute & 2.47 & 0.069 & 0.13 \\
\hline & Chronic & 2.47 & 0.070 & 0.13 \\
\hline \multirow[t]{2}{*}{ PGRP-LC } & Acute & 2.60 & 0.060 & 0.13 \\
\hline & Chronic & 1.69 & 0.166 & 0.22 \\
\hline \multirow{2}{*}{ PGRP-SB } & Acute & 2.26 & 0.086 & 0.13 \\
\hline & Chronic & 2.59 & 0.060 & 0.13 \\
\hline \multirow[t]{2}{*}{ PGRP-SD } & Acute & 1.46 & 0.22 & 0.26 \\
\hline & Chronic & 0.32 & 0.76 & 0.76 \\
\hline \multirow[t]{2}{*}{ relish } & Acute & 2.44 & 0.071 & 0.13 \\
\hline & Chronic & 2.57 & 0.061 & 0.13 \\
\hline \multirow[t]{2}{*}{ toll } & Acute & 1.05 & 0.352 & 0.40 \\
\hline & Chronic & 1.45 & 0.220 & 0.26 \\
\hline \multirow[t]{2}{*}{ TotA-1 } & Acute & 3.43 & $<0.001$ & 0.01 \\
\hline & Chronic & 11.59 & $<0.001$ & 0.01 \\
\hline \multirow[t]{2}{*}{ vir-1 } & Acute & 2.40 & 0.074 & 0.13 \\
\hline & Chronic & 0.06 & 0.0956 & 0.14 \\
\hline
\end{tabular}




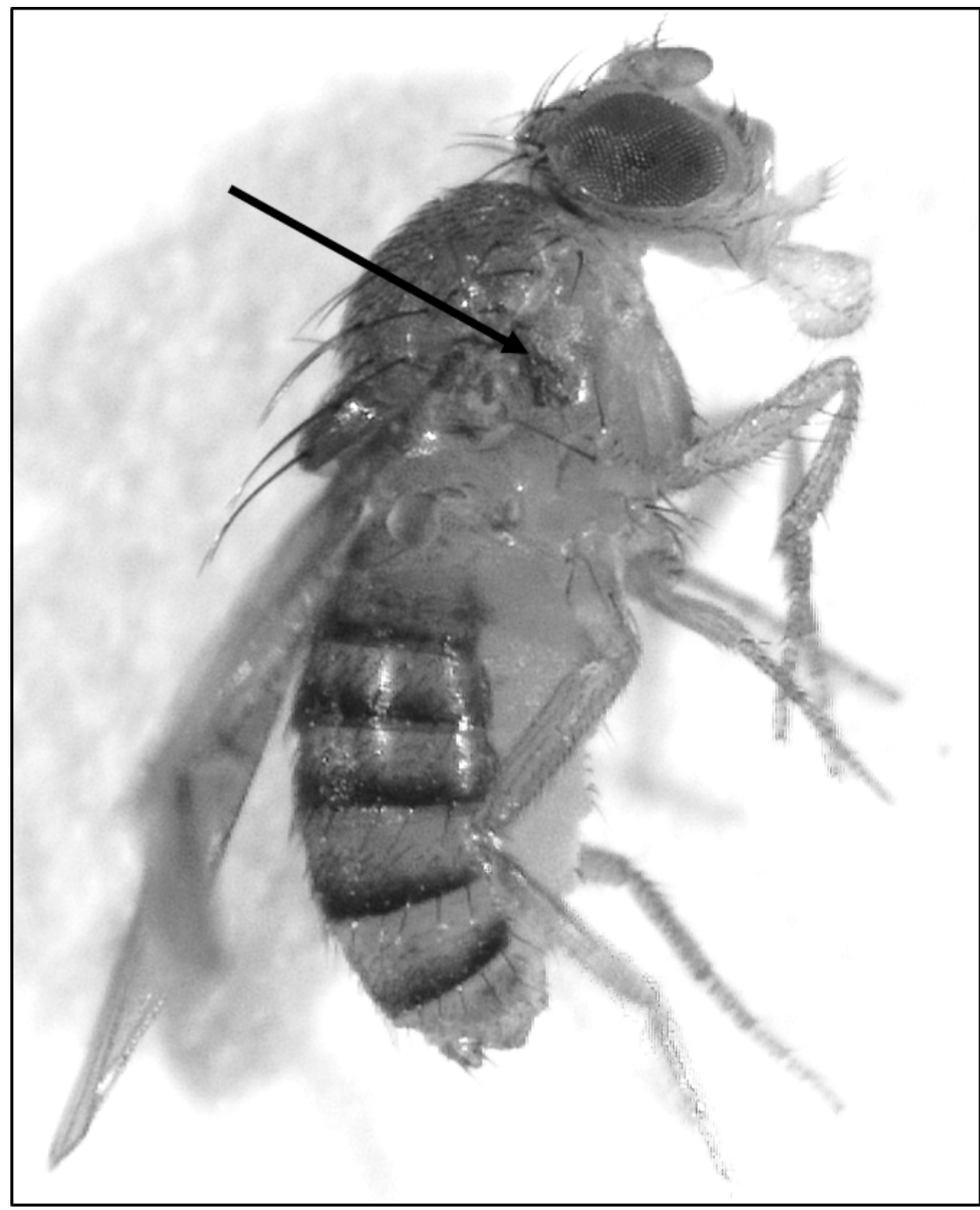

Figure S1. Location of piercing for wound-induced melanisation. Flies were pierced in the right thoracic vertical cleft along the notopleural suture until it reached the humeral callus, as indicated by the black arrow. 